\title{
The Pattern of Secreted Molecules During the Co-Inoculation of Alfalfa Plants With Sinorhizobium meliloti and Delftia sp. strain JD2: An Interaction That Improves Plant Yield
}

\author{
M. A. Morel, ${ }^{1}$ C. Cagide, ${ }^{1}$ M. A. Minteguiaga, ${ }^{1}$ M. S. Dardane $l i{ }^{2}{ }^{2}$ and S. Castro-Sowinski ${ }^{1,3}$ \\ ${ }^{1}$ Molecular Microbiology, Clemente Estable Institute of Biological Research, Montevideo, Uruguay; ${ }^{2}$ Department of Molecular \\ Biology, FCEFQYN, Universidad Nacional de Rio Cuarto, Córdoba, Argentina; ${ }^{3}$ Biochemistry and Molecular Biology, Faculty \\ of Science, University of the Republic, Igua 4225, Montevideo, Uruguay
}

Submitted 4 August 2014. Accepted 15 October 2014.

\begin{abstract}
Delftia sp. strain JD2 is a plant-growth-promoting bacterium that enhances legume nodulation and growth, acting as nodule-assisting bacterium during the co-inoculation of plants with rhizobial strains. In this work, we evaluate how the co-inoculation of alfalfa with Sinorhizobium meliloti U143 and JD2 increases plant yield under greenhouse conditions and we analyze the pattern of secreted bioactive compounds which may be involved in the microbe-plant communication. The chemical composition of extracellular cultures (EC) produced in hydroponic conditions (collected 4,7 , and 14 days after bacterial treatment) were characterized using different chromatographic and elucidation techniques. In addition, we assessed the effect that plant irrigation with cell-free EC, produced during co-inoculation experiments, would have on plant yield. Results showed increased alfalfa shoot and root matter, suggesting that U143-JD2 co-inoculation might be a beneficial agricultural practice. The pattern of secreted secondary metabolites among treatments showed important differences. Qualitative and quantitative changes in phenolic compounds (including flavonoids), organic acids, and volatile compounds were detected during the early microbe-plant interaction, suggesting that the production of some molecules positively affects the microbe-plant association. Finally, the irrigation of co-inoculated plants with cell-free EC under greenhouse conditions increased plant yield over agronomic expectations. This effect might be attributed to the bioactive secondary metabolites incorporated during the irrigation.
\end{abstract}

Leguminous plants are economic important crops. They are source of proteins (high protein content of some grains) and other nutrients, and are used as pastures. Pastures such as alfalfa and clover play an important role in dairy and meat production, being sources of protein, fiber, and energy (Phan Tran and Nguyen 2009). Thus, the ability of many legumes to form associations with plant-growth-promoting bacteria (PGPB) that increase plant yield is of high ecological and economic interest.

Corresponding author: S. Castro-Sowinski; Telephone: +(598) 25252095; E-mail: s.castro.sow@gmail.com; scs@fcien.edu.uy

(C) 2015 The American Phytopathological Society
The comparison between chemical and biological fertilization supports the idea that the uses of PGPB in commercial formulations represent an economic, sustainable, and environmentally friendly alternative to maintain nutritional needs of an agroecosystem (Morel et al. 2012).

The biological nitrogen $(\mathrm{N})$ fixation process in leguminous plants plays a very important role in terms of plant production in agriculture. Rhizobia are bacteria that fix atmospheric $\mathrm{N}$ when associate with leguminous plants. The $\mathrm{N}$ fixation is preceded by root morphological changes that include the rootnodule formation (where rhizobia are transformed into bacteroids and fix $\mathrm{N}$ as the result of the nitrogenase activity) (Morel and Castro-Sowinski 2013). Thus, rhizobia promote growth by increasing the $\mathrm{N}$ supply to the legume host plant. In addition, the enhanced nodulation by the combined inoculation with rhizobia and other PGPB has been reported for several legumes. This phenomenon may be mainly due to changes in root-exuded molecules such as flavonoids that increase the transcription of rhizobial nodulation genes (Dardanelli et al. 2008, 2012; Morel and Castro-Sowinski 2013; Narula et al. 2009; Volpin et al. 1996). However, other molecular factors in addition to flavonoids-for example, phytohormones, volatile organic compounds (VOC), quorum-sensing signaling molecules, extracellular polysaccharides, and proteins - have been involved in the establishment of the mutualistic interaction between legume and rhizobia (Morel and Castro-Sowinski 2013).

Microbial secreted hormones (auxins and cytokinins) influence plant cell division and differentiation, affecting root and shoot architecture and functioning. VOC may have antibiotic functions, induce different phytohormonal signaling networks, and activate immune systemic resistance and cytokinin-dependent pathways for plant growth promotion. The best-known roles attributed to plant flavonoids are in chemoattraction of rhizobia to the legume root and as a primary molecular signal for rhizobial nod-gene induction, followed by nodulation factor production. Extracellular polysaccharides have roles as protection against stress, attachment to surfaces, plant invasion, and inhibition of plant defense in plant-microbe interactions. For better information on molecular signaling in microbe-plant interaction, see Morel and Castro-Sowinski (2013).

Bacteria of the genus Delftia are Betaproteobacteria (family Comamonadaceae), recognized by their ability to promote plant growth (diazotrophic and biocontrol agents against various 
plant pathogens) (Morel and Castro-Sowinski 2013). They fix atmospheric $\mathrm{N}$, produce auxin indole-3-acetic acid (IAA) and siderophores, promote alfalfa and clover growth under N-rich conditions in gnotobiotic experiments, and assist as a "helper" bacterium during rhizobia-legume interaction, inducing early nodulation and increasing the number of nodules per plant (Han et al. 2005; Morel et al. 2011; Ubalde et al. 2012). These microorganisms might be used in cooperative association with rhizobia and exploited for developing new sustainable, environmentally friendly agrotechnological practices.

The general aim of this work was to contribute to the understanding of the communication network established between alfalfa plants and the bacterial consortium Sinorhizobium meliloti U143 and Delftia sp. strain JD2. We seek to answer the following questions. Does Delftia sp. strain JD2 associate with alfalfa roots and does co-inoculation with $S$. meliloti U143 have an effect on plants in the greenhouse? Does co-inoculation change the profile of extracellular components found in the growth media? Are these extracellular components the cause of the observed plant growth promotion? This work shows the importance and the potential of these compounds derived from legumes and rhizobacteria in biotechnology.

\section{RESULTS}

Does Delftia sp. strain JD2 associate with alfalfa roots and does co-inoculation with $S$. meliloti $\mathrm{U} 143$ have an effect on plants in the greenhouse?

The ability of Delftia sp. strain JD2 to improve biomass production and to colonize the root, during inoculation and coinoculation experiments, was assessed as described below in the sections "Plant assay" and "Visualization of JD2 infection", respectively. Results are shown in Table 1 and Figure 1.

Co-inoculation increased shoot and root matter (measured as dry weight) up to 13 and $34 \%$, respectively, over U143-inoculated plants. Single JD2 inoculation did not increase shoot yield but increased root yield by $12 \%$ compared with a single inoculation with U143, suggesting that JD2 affects alfalfa root development (Table 1).

Epifluorescence microscopy experiments showed the colonization of alfalfa roots by JD2 (Fig. 1). At 4 days after inoculation, JD2 cells were found in the emergent lateral roots of alfalfa, and 3 days after bacterial cells were observed following the longitudinal root cell wall (including root nodules surface).

\section{Does co-inoculation change the profile of extracellular components found in the growth media?}

Secreted molecules during the microbe-plant interaction were analyzed using different chromatographic procedures, in a temporal fashion, as indicated below (section "Chemical identification and quantification of molecules"). Cell-free extracellular cultures (EC) were prepared as described in the section "Hydroponic experiments and collection of EC". During this study, we did not discriminate between plant roots or bacterial secreted molecules.

Results of liquid-chromatography mass spectrometry (LCMS) and gas-chromatography mass spectrometry (GC-MS) analysis are shown in Tables 2 to 5 . A general overview of results suggests the relationship between plant age and exudates composition, shown by a different molecular composition over time.

Apigenin, chrysin, and genistein were the main flavonoids exuded by alfalfa under uninoculated conditions, with maximum values of flavonoid exudation in 4-day-old seedling. Their concentrations were dramatically reduced 7 days after inoculation, suggesting that flavonoids might be degraded or used by the plant or microbes (Table 2).
The analysis also showed that most tested flavonoids were present at higher concentrations at the early stage (4 days compared with 7 and 15 days after inoculation) of the microbeplant interaction, mainly during co-inoculation experiments. On average, three-, two-, three-, and threefold inductions in apigenin, chrysin, genistein, and naringin production, respectively, were detected in co-inoculation experiments compared with U143 single inoculation. Morin was not detected, and the plant flavanone naringenin content diminished 190-fold in exudates obtained in co-inoculation experiments.

Luteolin was detected at unexpectedly low concentration in all conditions. Luteolin secretion by alfalfa was low (compared with others flavonoids) but 7- and 146-fold induction were found during JD2-inoculation and co-inoculation experiments (4-day-old seedlings), respectively. Later, luteolin concentration significantly decreased but always showed higher (60 to 120 times) concentration in co-inoculated EC compared with U143-inoculated EC (Table 2).

The time course secretion of IAA and the amino acid tryptophan (Trp) (biosynthetic precursor of IAA) is shown in Table 2. The phytohormone IAA was not found in uninoculated hydroponic experiments but was found in inoculated treatments, when Trp was not detected. Trp was detected during the early stage (4 days after inoculation) of the microbe-plant interaction, and probably was totally consumed 3 days after, during IAA biosynthesis. The concentration of IAA was higher in coinoculated hydroponic experiments than in single-inoculation (JD2 or U143) experiments.

GC-based metabolite profiling was used to analyze the time course secretion of low-molecular-weight (LMW) compounds. Only chromatographic peaks with a signal/noise ratio of three or higher were considered and their chemical nature was identified. Many metabolites, including fatty acids (FA), amino acids, organic acids, and carbohydrates, were detected (Tables 3 to 5$)$.

Slight differences were found in the pattern of LMW secreted molecules at the early stage of the interaction. Compounds present at 4 days are the terpene limonene, a VOC plant derived with antioxidant activity that might be secreted during the inoculation with U143, and many organic acids commonly found in EC.

Over time ( 7 and 15 days after inoculation), when the concentration of flavonoids declined, EC showed a very diverse profile of LMW molecules among treatments (Tables 4 and 5). Many organic acids (derived from FA oxidation and lignin degradation) were detected, including dicarboxylic acids (succinic, pyruvic, adipic, and malic), monocarboxylic acids (acetic and lactic, butyric, and hydroxybutyric), and benzenic acids (cinnamic and benzoic). A wide spectrum of FA was detected but no clear trend was identified. The monosaccharide and FA composition of EC collected 4 days after inoculation was also

Table 1. Effect of Delftia sp. strain JD2 on alfalfa growth under greenhouse conditions

\begin{tabular}{lcc}
\hline & \multicolumn{2}{c}{ Weight (mg/plant) } \\
\cline { 2 - 3 } Treatment & SDW & RDW \\
\hline Nonfertilized and uninoculated & $120 \pm 8 \mathrm{~b}$ & $270 \pm 50 \mathrm{c}$ \\
Inoculation with JD2 & $130 \pm 6 \mathrm{~b}$ & $300 \pm 60 \mathrm{bc}$ \\
Inoculation with U143 & $150 \pm 2 \mathrm{cb}$ & $270 \pm 20 \mathrm{c}$ \\
Co-inoculation with JD2 and U143 & $170 \pm 26 \mathrm{c}$ & $360 \pm 50 \mathrm{ab}$ \\
N fertilized & $280 \pm 30 \mathrm{a}$ & $450 \pm 60 \mathrm{a}$ \\
\hline
\end{tabular}

${ }^{\mathrm{z}} \mathrm{SDW}=$ shoot dry weight and RDW $=$ root dry weight. Results (mean \pm standard deviation) expressed as milligrams of dry matter per plant are from one of three independent experiments with a similar trend. Different letters indicate significant difference among treatments $(P<$ $0.05)$. 
analyzed by GC-flame ionization detector (FID). N-fertilized and JD2- and U143-inoculated EC showed a similar relative sugar composition ( $25 \%$ ribose, $25 \%$ celobiose+galactose, and $50 \%$ glucose). Interestingly, $100 \%$ glucose was detected in coinoculated EC. GC-FID analysis confirmed the profile of FA detected by GC-MS, except that the lignoceric acid was detected in co-inoculated EC.

\section{Are these extracellular components the cause of the observed plant growth promotion?}

Most of the molecules that are already known to be involved in the microbe-plant interaction were detected during the early stage of the interaction; thus, we decided to study how plants respond when they are irrigated with cell-free EC, collected 4 days after co-inoculation, under greenhouse conditions, as described in "Plant assay".

The statistical analysis did not show differences in the values of shoot dry weight (SDW) and root dry weight (RDW) among EC-irrigated plants, regardless of treatment. However, significant differences were detected between EC-irrigated and water-irrigated treatments (Table 6). Results showed that SDW and RDW statistically increased in plants subjected to single (JD2 or U143) or double inoculation (co-inoculation with JD2 and U143) when irrigated with EC but did not in N-fertilized control plants (Table 6), suggesting that the cocktail of molecules in EC might assist in the microbe-plant communication
A

1

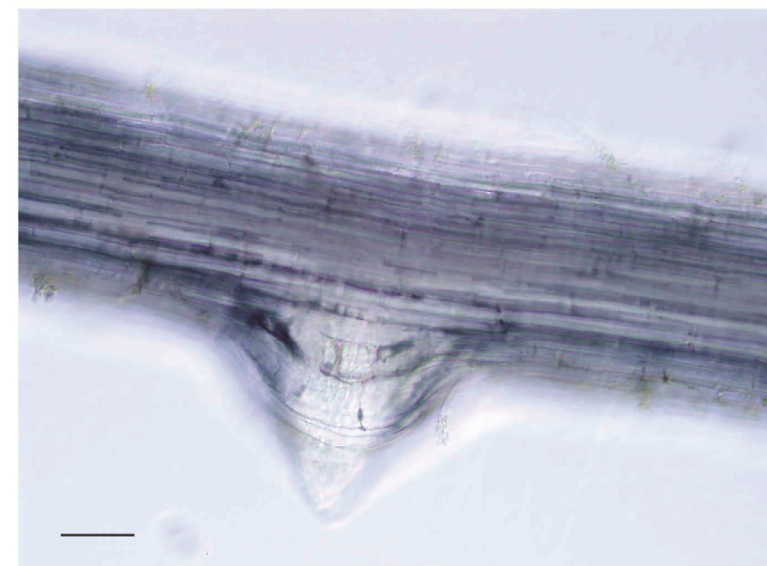

2

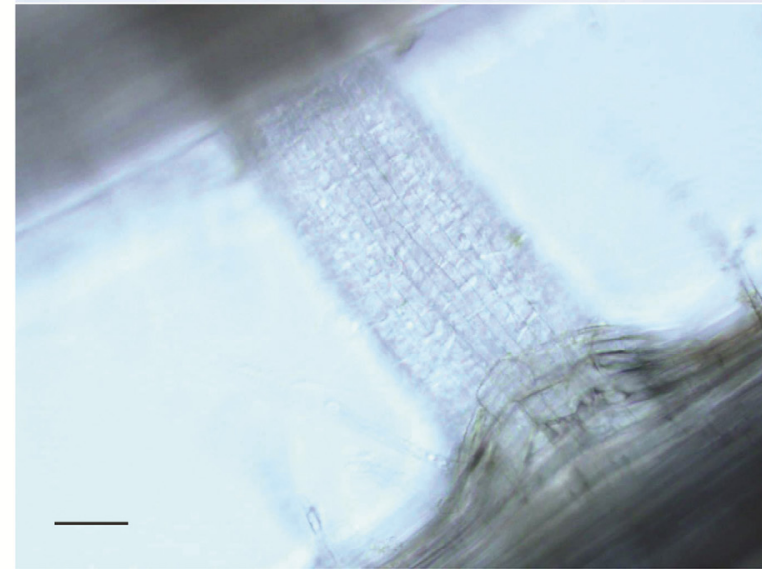

3

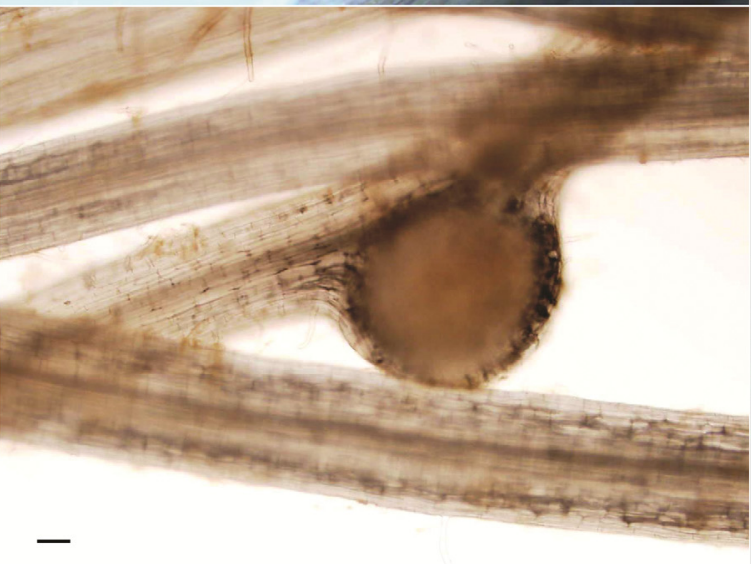

B
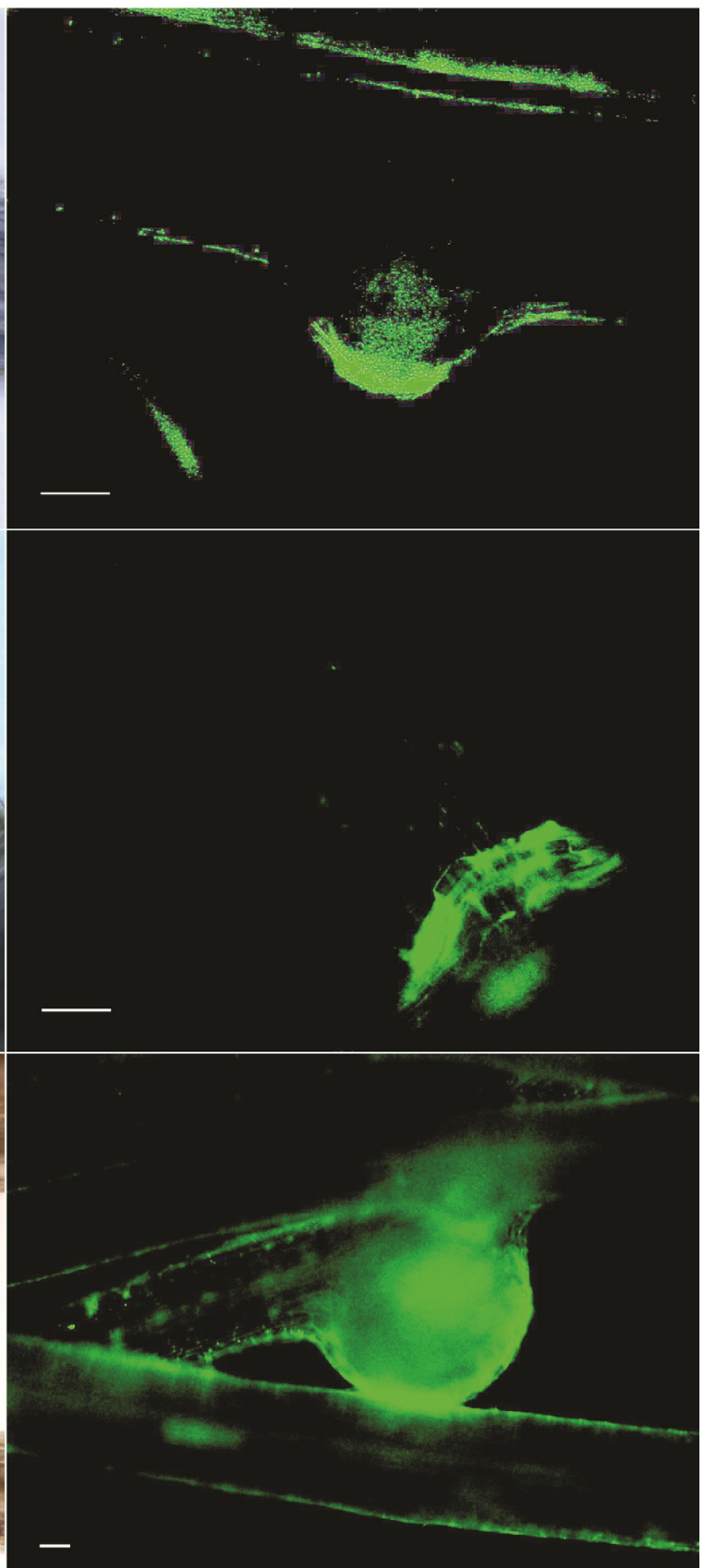

Fig. 1. Root colonization by Delftia sp. strain JD2. A, Transmitted light and B, fluorescence microscopy of alfalfa roots row 1, 4 days after inoculation with JD2 (growing root tips are shown emerging from the principal root base); row 2, 4 days after co-inoculation (growing root tips are shown emerging from the principal root base); and row 3, 7 days after co-inoculation (root nodule) Bar $=77.06 \mu \mathrm{m}$. Fluorescence was not detected in control roots (noninoculated plants) or on nodules of plants inoculated with U143. 
during the microbe-plant interaction, and not through a direct effect on the plant.

In general, the addition of EC increased plant growth but the major effect was observed in RDW, with increments of 19 and $44 \%$ in co-inoculated and U143-inoculated plants, respectively (Table 6). Although IAA was not detected in EC collected 4 days after co-inoculation, the Trp (already detected in these EC) might be a source of precursors for the bacterial production of IAA that might account for the root growth promotion in greenhouse experiments.

\section{DISCUSSION}

Previous results showed that nodulation significantly improved (early nodulation and more nodules per root) when alfalfa plants were co-inoculated with $S$. meliloti U143 and Delftia sp. strain JD2 compared with single inoculation in gnotobiotic conditions (Morel et al. 2011). In this work, we assessed the co-inoculation of alfalfa under greenhouse conditions. Results showed an increase of 13 and $33 \%$ in shoot and root weight, respectively, when alfalfa plants were co-inoculated compared with single rhizobial inoculation. On average, an increase of 4 to $5 \%$ in crop yield has an important impact in agricultural production. The data obtained in greenhouse experiments show that co-inoculation increased alfalfa yield, overcoming the agronomic expectations.

Results from many studies concerning the effect of co-inoculation on legume growth were summarized by Morel and associates (2012). The best-known genera identified as "helpers" of the rhizobia-legume symbiotic process are Azospirillum (Cassán et al. 2009; Itzigsohn et al. 1993), Bacillus (Bullied et al. 2002; Mishra et al. 2009), and Pseudomonas (Egamberdieva et al. 2010; Fox et al. 2011), among others. Our data support the idea that Delftia sp. strain JD2 is a helper bacterium that assists during the alfalfa-sinorhizobia interaction, improving alfalfa yield under greenhouse conditions. Thus, we propose that Delftia may be included in the list of bacteria potentially useful in industrial formulations.

\section{Secretome analysis.}

Understanding the role that the molecules (commonly found in EC) have during the plant-microbe interaction might help to design new strategies to improve agronomical practices. Our hypothesis of work implied that the presence of the plant root is required for bacteria to secrete molecules involved in the microbe-plant interaction, and all of our experiments included

Table 2. Chemical composition of root exudates: flavonoids $(\mu \mathrm{M})$, indole-3-acetic acid (IAA; nM), and tryptophan $(\operatorname{Trp} ; \mu \mathrm{M})^{\mathrm{z}}$

\begin{tabular}{|c|c|c|c|c|c|c|c|c|c|}
\hline \multirow[b]{2}{*}{ Treatment, DAI } & \multicolumn{3}{|c|}{ Flavone } & \multicolumn{2}{|c|}{ Flavanone } & \multirow{2}{*}{$\begin{array}{l}\text { Flavone } \\
\text { Luteolin }\end{array}$} & \multirow{2}{*}{$\begin{array}{c}\text { Flavonol } \\
\text { Morin }\end{array}$} & \multirow[b]{2}{*}{ IAA } & \multirow[b]{2}{*}{ Trp } \\
\hline & Apigenin & Chrysin & Genistein & Naringenin & Naringin & & & & \\
\hline \multicolumn{10}{|c|}{ Uninoculated control } \\
\hline 4 & $3.464 \mathrm{a}$ & $4.327 \mathrm{a}$ & $3.400 \mathrm{a}$ & $0.087 \mathrm{a}$ & $0.098 \mathrm{a}$ & $0.586 \mathrm{a}$ & ND & ND & ND \\
\hline 7 & $0.007 \mathrm{~b}$ & $0.300 \mathrm{~b}$ & $0.005 \mathrm{~b}$ & $0.162 \mathrm{a}$ & ND & $0.013 \mathrm{bc}$ & ND & ND & ND \\
\hline 15 & $0.017 \mathrm{~b}$ & $0.576 \mathrm{c}$ & $0.035 \mathrm{~b}$ & $0.810 \mathrm{~b}$ & $0.041 \mathrm{a}$ & $0.014 \mathrm{bc}$ & ND & ND & $0.06 \mathrm{a}$ \\
\hline \multicolumn{10}{|c|}{ Inoculated with U143 } \\
\hline 4 & $6.715 \mathrm{c}$ & $9.903 \mathrm{~d}$ & $6.340 \mathrm{c}$ & $11.271 \mathrm{c}$ & $0.105 \mathrm{a}$ & $0.021 \mathrm{bc}$ & ND & $4.0 \mathrm{a}$ & $0.20 \mathrm{a}$ \\
\hline 7 & $0.152 \mathrm{~b}$ & $0.036 \mathrm{e}$ & $0.117 \mathrm{~b}$ & $0.492 \mathrm{~d}$ & $0.036 \mathrm{a}$ & $0.004 \mathrm{bc}$ & ND & $2.4 \mathrm{~b}$ & ND \\
\hline 15 & $1.662 \mathrm{~b}$ & $1.688 \mathrm{f}$ & $0.336 \mathrm{~d}$ & $2.665 \mathrm{e}$ & $0.039 \mathrm{a}$ & $0.001 \mathrm{~b}$ & ND & ND & $0.18 \mathrm{a}$ \\
\hline \multicolumn{10}{|c|}{ Inoculated with JD2 } \\
\hline 4 & $0.276 \mathrm{~b}$ & $4.318 \mathrm{a}$ & $0.730 \mathrm{e}$ & $2.253 \mathrm{f}$ & $0.089 \mathrm{a}$ & $0.149 \mathrm{bcd}$ & ND & ND & $0.16 \mathrm{a}$ \\
\hline 7 & $0.026 \mathrm{~b}$ & ND & $0.030 \mathrm{~b}$ & $0.007 \mathrm{a}$ & ND & ND & ND & $3.9 \mathrm{a}$ & ND \\
\hline 15 & $0.140 \mathrm{~b}$ & ND & $0.084 \mathrm{bd}$ & $0.577 \mathrm{~g}$ & ND & $0.035 \mathrm{bcd}$ & ND & ND & $0.01 \mathrm{a}$ \\
\hline \multicolumn{10}{|c|}{ Co- inoculated with JD2 and U143 } \\
\hline 4 & $18.030 \mathrm{~d}$ & $19.393 \mathrm{~g}$ & $17.419 \mathrm{f}$ & $0.060 \mathrm{a}$ & $0.324 \mathrm{~b}$ & $3.073 \mathrm{e}$ & ND & ND & $0.15 \mathrm{a}$ \\
\hline 7 & $0.965 \mathrm{~b}$ & $8.780 \mathrm{~h}$ & $0.956 \mathrm{a}$ & $0.909 \mathrm{~b}$ & $0.018 \mathrm{a}$ & $0.260 \mathrm{~d}$ & ND & $4.7 \mathrm{c}$ & ND \\
\hline 15 & $0.001 \mathrm{~b}$ & $1.178 \mathrm{i}$ & $0.012 \mathrm{~b}$ & $0.373 \mathrm{~d}$ & $0.040 \mathrm{a}$ & $0.126 \mathrm{bc}$ & ND & ND & $0.02 \mathrm{a}$ \\
\hline
\end{tabular}

${ }^{\mathrm{z}}$ Alfalfa plants grown in hydroponic systems were inoculated with Delftia sp. strain JD2 or S. meliloti U143. Composition was analyzed 4, 7, and 15 days after inoculation. DAI = days after inoculation and $\mathrm{ND}=$ not detected. Results are from one of three independent experiments with similar trends. Different letters indicate a significant difference among treatments in each column $(P<0.05)$.

Table 3. Chemical composition of root exudates (4 days after bacterial treatment): low molecular weight (trimethylsylil derivatives) ${ }^{\mathrm{z}}$

\begin{tabular}{|c|c|c|c|c|}
\hline Chemical family & All treatments & Inoculation with U143 & Inoculation with JD2 & Co-inoculation \\
\hline \multirow[t]{4}{*}{ Fatty acids } & Propanoic acid (C3:0) & $\cdots$ & Nonanoic acid (C9:0) & Nonanoic acid (C9:0) \\
\hline & Myristic acid (C14:0) & $\ldots$ & $\ldots$ & Oleic acid $(\mathrm{C} 18: 1$ cis- $\Delta 9)$ \\
\hline & Palmitic acid (C16:0) & $\ldots$ & $\ldots$ & $\ldots$ \\
\hline & Stearic acid (C18:0) & $\ldots$ & $\ldots$ & $\ldots$ \\
\hline Terpenes & & Limonene & $\ldots$ & Limonene \\
\hline Volatile organic compounds & Butanediol & $\ldots$ & $\ldots$ & $\ldots$ \\
\hline Phenolic compounds & Cinnamic acid & $\ldots$ & $\ldots$ & Benzoic acid \\
\hline \multirow[t]{5}{*}{ Organic acid and derivatives } & Isopropylmalic acid & $\ldots$ & Malonic acid & Hydroxybutyric acid \\
\hline & Monopalmitin & $\ldots$ & $\ldots$ & $\ldots$ \\
\hline & Adipic acid & $\ldots$ & $\ldots$ & $\ldots$ \\
\hline & Lactic acid & $\ldots$ & $\ldots$ & $\ldots$ \\
\hline & Acetic acid & & & \\
\hline \multirow[t]{2}{*}{ Amides, amines and other $\mathrm{N}$-compounds } & Unidentified amides & Caproic amide & $\ldots$ & Caproic amide \\
\hline & Urea & $\ldots$ & $\ldots$ & $\ldots$ \\
\hline \multirow[t]{2}{*}{ Carbohydrates and Polyols } & $\ldots$ & $\ldots$ & Arabinose & $\ldots$ \\
\hline & $\ldots$ & $\ldots$ & Inositol & $\ldots$ \\
\hline
\end{tabular}

${ }^{\mathrm{z}}$ Compounds included in the column named "All treatments" were detected in all treatments, including nonbacterized controls. Compounds exclusively found in a specific treatment were indicated in the corresponding column. In all cases of compounds reported, differences between theoretical and experimental calculated linear retention index values were smaller than 10 units, confirming mass spectrometry identification. Results are from one of three independent experiments. 
Table 4. Chemical composition of root exudates (7 days after bacterial treatment): low molecular weight (trimethylsylil derivatives) ${ }^{\mathrm{Z}}$

\begin{tabular}{|c|c|c|c|c|}
\hline Chemical family & All treatments & Inoculation with U143 & Inoculation with JD2 & Co-inoculation \\
\hline \multirow[t]{5}{*}{ Fatty acids } & Palmitic acid (C16:0) & Nonanoic acid (C9:0) & Nonanoic acid (C9:0) & Nonanoic acid (C9:0) \\
\hline & Stearic acid (C18:0) & Lauric acid (C12:0) & $\ldots$ & Capric acid(C10:0) \\
\hline & $\ldots$ & $\ldots$ & $\ldots$ & Oleic acid $(\mathrm{C} 18: 1 \mathrm{cis}-\Delta 9)$ \\
\hline & $\ldots$ & $\ldots$ & $\ldots$ & Lauric acid (C12:0) \\
\hline & $\ldots$ & $\ldots$ & $\ldots$ & Myristic acid (C14:0) \\
\hline \multirow[t]{3}{*}{ Carboxylic acid and derivatives } & Monopalmitin & Succinic acid & Lactic acid & Lactic acid \\
\hline & $\ldots$ & $\ldots$ & Acetic acid & Piruvic acid \\
\hline & $\ldots$ & $\ldots$ & $\ldots$ & Adipic acid \\
\hline \multirow{5}{*}{$\begin{array}{l}\text { Amides, amines, amino acids, and } \\
\text { other N-compounds }\end{array}$} & & & & \\
\hline & Succinic acid imide & $\ldots$ & Urea & 2-Aminoethanol \\
\hline & $\ldots$ & $\ldots$ & $\ldots$ & Urea \\
\hline & $\ldots$ & $\ldots$ & $\ldots$ & Serine \\
\hline & $\ldots$ & $\ldots$ & $\ldots$ & Homoserine \\
\hline \multirow[t]{3}{*}{ Carbohydrates and Polyols } & Glycerol & Inositol & Inositol & Galactose \\
\hline & $\ldots$ & $\ldots$ & $\ldots$ & Glucose \\
\hline & $\ldots$ & $\ldots$ & $\ldots$ & Sucrose \\
\hline
\end{tabular}

${ }^{\text {z }}$ Compounds included in the column named "All treatments" were detected in all treatments, including nonbacterized controls. Compounds exclusively found in a specific treatment were indicated in the corresponding column. In all cases of compounds reported, differences between theoretical and experimental calculated linear retention index values were smaller than 10 units, confirming mass spectrometry identification. Results are from one of three independent experiments.

Table 5. Chemical composition of root exudates (15 days after bacterial treatment): low molecular weight (trimethylsylil derivatives) ${ }^{\mathrm{z}}$

\begin{tabular}{|c|c|c|c|c|}
\hline Chemical family & All treatments & Inoculation with U143 & Inoculation with JD2 & Co-inoculation \\
\hline \multirow[t]{6}{*}{ Fatty acids } & Nonanoic acid (C9:0) & Myristic acid (C14:0) & Lauric acid (C12:0) & Butyric acid (C4:0) \\
\hline & Palmitic acid (C16:0) & Pentadecanoic acid (C15:0) & Oleic acid (C18:1 cis- $\Delta 9)$ & Caproic acid (C6:0) \\
\hline & Stearic acid (C18:0) & $\ldots$ & $\ldots$ & Capric acid (C10:0) \\
\hline & $\ldots$ & $\ldots$ & $\ldots$ & Lauric acid (C12:0) \\
\hline & $\ldots$ & $\ldots$ & $\ldots$ & Myristic acid (C14:0) \\
\hline & $\ldots$ & $\ldots$ & $\ldots$ & Oleic acid $(\mathrm{C} 18: 1 \mathrm{cis}-\Delta 9)$ \\
\hline Volatile organic compounds & $\ldots$ & Propanediol & $\ldots$ & Methyl benzoate \\
\hline \multirow[t]{5}{*}{ Carboxylic acid and derivatives } & Monopalmitin & Lactic acid & Lactic acid & Glicolic acid \\
\hline & $\ldots$ & Adipic acid & Succinic acid & Acetic acid \\
\hline & $\ldots$ & $\ldots$ & Adipic acid & $\ldots$ \\
\hline & $\ldots$ & $\ldots$ & Azelaic acid & $\ldots$ \\
\hline & $\ldots$ & $\ldots$ & Benzoic acid & $\ldots$ \\
\hline \multirow[t]{4}{*}{ Amino acids, amines, and other $\mathrm{N}$-compounds } & $\ldots$ & Carbonyl diamide & Urea & $\ldots$ \\
\hline & $\ldots$ & Serine & Serine & $\ldots$ \\
\hline & $\ldots$ & Homoserine & Threonine & $\ldots$ \\
\hline & $\ldots$ & $\ldots$ & Homoserine & $\ldots$ \\
\hline \multirow[t]{12}{*}{ Carbohydrates and Sugar alcohol } & Ribose & Mannose & Arabinose & Xilulose \\
\hline & Glucose & $\ldots$ & Mannose & Gulonic acid lactone \\
\hline & Galactose & $\ldots$ & Ribonic acid & Glycerol \\
\hline & myo-Inositol & $\ldots$ & Xylose & Xylitol \\
\hline & $\ldots$ & $\ldots$ & Fructose & $\ldots$ \\
\hline & $\ldots$ & $\ldots$ & Sucrose & $\ldots$ \\
\hline & $\ldots$ & $\ldots$ & Lactose & $\cdots$ \\
\hline & $\ldots$ & $\ldots$ & Maltose & $\ldots$ \\
\hline & $\ldots$ & $\ldots$ & Erythritol & $\ldots$ \\
\hline & $\ldots$ & $\ldots$ & Xylitol & $\ldots$ \\
\hline & $\ldots$ & $\ldots$ & Arabitol & $\ldots$ \\
\hline & $\ldots$ & $\ldots$ & Glycerol & $\ldots$ \\
\hline Pyridine derivatives & $\ldots$ & $\ldots$ & Nicotinic acid & $\ldots$ \\
\hline
\end{tabular}

${ }^{z}$ Compounds included in the column named "All treatments" were detected in all treatments, including nonbacterized controls. Compounds exclusively found in a specific treatment were indicated in the corresponding column. In all cases of compounds reported, differences between theoretical and experimental calculated linear retention index values were smaller than 10 units, confirming mass spectrometry identification. Results are from one of three independent experiments.

Table 6. Effect of cell-free extracellular culture (EC) in alfalfa yield ${ }^{\mathrm{z}}$

\begin{tabular}{|c|c|c|c|c|}
\hline \multirow[b]{2}{*}{ Treatment } & \multicolumn{2}{|c|}{ SDW (mg/plant) } & \multicolumn{2}{|c|}{ RDW (mg/plant) } \\
\hline & $+\mathrm{EC}$ & $-\mathbf{E C}$ & $+\mathrm{EC}$ & $-\mathbf{E C}$ \\
\hline Nonfertilized and uninoculated & $223 \pm 25 b$ & $120 \pm 8 \mathrm{~d}$ & $315 \pm 40 \mathrm{dbc}$ & $270 \pm 50 \mathrm{dbc}$ \\
\hline Inoculation with JD2 & $225 \pm 21 b$ & $127 \pm 60 \mathrm{~d}$ & $318 \pm 40 \mathrm{dbc}$ & $296 \pm 58 \mathrm{dbc}$ \\
\hline Inoculation with U143 & $220 \pm 16 b$ & $149 \pm 21 \mathrm{~cd}$ & $475 \pm 38 \mathrm{a}$ & $267 \pm 10 b$ \\
\hline Co-inoculation with JD2 and U143 & $207 \pm 17 \mathrm{eb}$ & $170 \pm 30 \mathrm{ed}$ & $442 \pm 25 \mathrm{a}$ & $360 \pm 50 \mathrm{~d}$ \\
\hline $\mathrm{N}$ fertilized & $262 \pm 14 \mathrm{a}$ & $281 \pm 26 \mathrm{a}$ & $448 \pm 59 a$ & $421 \pm 41 \mathrm{a}$ \\
\hline
\end{tabular}

${ }^{\mathrm{z}}$ Cell-free EC were prepared and used once as watering solution in greenhouse experiments. Four conditions were evaluated: alfalfa plants inoculated with JD2 or U143, co-inoculated with JD2 and U143, and N fertilized. SDW = shoot dry weight and RDW = root dry weight; +EC = irrigation with cell-free EC and $-\mathrm{EC}=$ control plants irrigated with water. Results (mean \pm standard deviation), expressed as milligrams of dry matter per plant, are from one of three independent experiments with similar trend each. Different letters indicate significant differences among treatments $(P<0.05)$. 
the plant root. However, it is important to indicate the possibility that at least some of the growth stimulation molecules may result from the interaction between both bacteria (U143 and JD2), even in the absence of plant root.

The chemical analysis of EC showed that most tested flavonoids were present at higher concentrations 4 days after bacterial treatment rather than at 7 and 15 days after inoculation (when nodulation was already established). In addition, the concentration of flavonoids was higher in co-inoculated experiments than in uninoculated control plants and in single-inoculated treatments. These results might suggest that the plant had recognized both microorganisms (U143 and JD2) as beneficial partners, as also suggested by Juge and associates (2012) when working with Bradyrhizobium and Azospirillum in association with soybean.

The concentration of luteolin was unexpectedly low (compared with others flavonoids) but this result might be attributed to our experimental design. The time-zero of hydroponic experiments were defined when 5-day-old seedlings were transferred to a fresh mineral medium before inoculation. Luteolin is mainly found in seed extracts (but not in alfalfa roots) (Hartwig et al. 1990; Zhang et al. 2007) and it was probably present in the solution discarded previous to inoculation. The plant flavone luteolin is the main S. meliloti nodulation gene inducer (Peters and Long 1988) and acts as a chemoattractant molecule (Caetano-Anollés et al. 1988). Thus, the increment in luteolin level (observed in JD2-inoculated and co-inoculated EC) suggests that JD2 cells have the ability to modify the secretion of alfalfa nod-gene-inducing flavonoids such as luteolin, among others. Interestingly, a reduction in naringenin level was observed in co-inoculated treatments. Naringenin has antagonistic activity toward the expression of sinorhizobial nodulation genes (Peters et al. 1986) and abolishes chemotaxis to luteolin (Caetano-Anollés et al. 1988). Thus, the reduction of naringenin level might reinforce the positive effect of luteolin during the microbe-plant interaction.

Most legumes release root-diffusible attractant signal molecules such as flavonoids, which trigger rhizobial production of nodulation factors (NF). NF are among the most important molecules in the microbe-plant dialog, mediating rhizobia recognition by the plant root and nodule organogenesis (Morel and Castro-Sowinski 2013). Although we did not determine the presence of $\mathrm{NF}$, the increased concentration of some plant flavonoids (especially luteolin) in EC, may suggest that the production and secretion of NF was also increased, as reported by Volpin et al. (1996). In summary, our results suggest that, during co-inoculation, the balance of flavonoids (kind and quantity; either nodulation gene activators or repressors) may play a role on the nodulation control and chemotaxis.

An inverse correlation between Trp and IAA levels was detected (Table 2), suggesting that the plant-excreted Trp (by roots to rhizosphere) was probably used for the synthesis of IAA. Results showed the secretion of IAA when plants were inoculated and co-inoculated with JD2, matching with the moment in which no Trp was detected and the concentration of flavonoids drastically decreased. Thus, the IAA was probably detected and used as a signal during plant cell growth. The results suggest a time course of molecular events during the microbe-plant interaction. During early stages (4 days after inoculation), flavonoids were the main molecular marker that signaled for the NF biosynthesis and, later (7 days), the secretion of the phytohormone IAA was the dominant signal leading for root proliferation. The phenotype associated with the proliferation of alfalfa roots due to the bacterial secretion of the auxin IAA during co-inoculation experiments was summarized by Morel and Castro-Sowinski (2013).
Many organic acids, including FA, and carbohydrates were detected by GC-MS in all treatments. Oxalic, malic, fumaric, succinic, acetic, lactic, pyruvic, malonic, and glutaric are the most common organic acids that have been identified in EC of different plant species (Bertin et al. 2003; Dakora and Phillips 2002; Jones 1998; Neumann 2007; Sandnes et al. 2005; Shukla et al. 2011). They act as nutrient source, improve plant availability of some nutrients, and reduce $\mathrm{pH}$, aiding in the solubilization of cations (Bertin et al. 2003; Dakora and Phillips 2002; Khorassani et al. 2011; Sandnes et al. 2005). The release of large amounts of organic acids to the rhizosphere was also expected because they induce the growth of preexisting rhizobacteria and act as chemoattractants for microbes toward the roots. We also detected nicotinic, adipic, benzoic, lignoceric, and cinnamic acids, all recognized as lignin derivatives usually found in EC (Shukla et al. 2011). In general, the plant cell wall increases the content of lignin as a response to pathogens (Jayamohan and Kumudini 2011). Thus, if U143 and JD2 are not recognized as pathogens, the secretion of lignin derivatives in co-inoculated EC may reflect an increased plant cell wall flexibility that helps root colonization by rhizobia.

Many FA commonly found in EC were detected: palmitic (16:0), oleic (18:1), and stearic (18:0), among others (Badri and Vivanco 2009; Dutta et al. 2013). Although no clear trend in FA profile was detected among EC, unsaturated and short-chainlength FA were mainly found in co-inoculated EC. These FA are involved in membrane fluidity and may reflect changes in the plant cell membrane fluidity necessary for bacterial root colonization, as suggested by Brechenmacher and associates (2010) when working on the Bradyrhizobium colonization of soybean. In addition, the long-chain-length lignoceric acid was detected by GC-FID in co-inoculated EC during an early stage of infection. Although the function of lignoceric acid in the microbeplant interaction is unknown, the accumulation of lignoceric acid was detected in soybean roots after $48 \mathrm{~h}$ of inoculation with Bradyrhizobium japonicum (Brechenmacher et al. 2010), and it was involved in the interaction between maize and the consortium formed by arbuscular mycorrhizal fungi and helper bacteria (Azotobacter, Azospirillum, Rhizobium, or Pseudomonas spp.) (Rajesh Kannan et al. 2011). Curiously, the exogenous application of very long fatty acids, such as lignoceric acid (C24:0), was directly involved in polar auxin transport and distribution in lateral roots, as shown in Arabidopsis (Roudier et al. 2010).

Among detected plant-growth-promoting VOC, butanediol was found in all treatments. Butanediol is responsible for the activation of the cytokinin-dependent and ethylene-dependent signaling pathways that induce systemic resistance (Ping and Boland 2004). The VOC limonene (monoterpene with antioxidant activity) was detected only in co-inoculated and U143inoculated EC, collected 4 days after inoculation. The increase of limonene content in soybean seed inoculated with Bradyrhizobium spp. was previously reported (Silva et al. 2013). Limonene prevents dehydration, induces defenses against predators (secreted as alarm or trail pheromones), inhibits growth of some potential pathogenic microbes (Bennett et al. 2012; Duetz et al. 2003), and may be used as a carbon source by some microorganisms (Duetz et al. 2003).

The detection of sugars and polyols was only relevant during the later stage of infection (15 days after inoculation). Polyols are involved in drought saline stress tolerance through the stabilization of membranes and proteins in alfalfa and soybean (Brechenmacher et al. 2010).

\section{Plant growth promotion.}

Legume roots exude flavonoids that induce the expression of the rhizobial nod genes which, in turn, control the synthesis of NF, which are bacteria-to-plant signal molecules (Macchiavelli 
and Brelles-Mariño 2004). In our study, we investigated whether the complex cocktail of molecules present in EC has an effect per se on plant growth.

A general overview of Table 6 shows that the irrigation of alfalfa plants (inoculated and co-inoculated) with EC under greenhouse conditions increases shoot yield and root system. Thus, results support the idea that rhizospheric exudates might have an important role in the establishment of the plant-bacteria interaction, enhancing the performance of rhizobial strains during co-inoculation of alfalfa. This effect might be due to the production of active metabolites that assist during the microbeplant interaction.

The addition of bacterial metabolites in the performance of the microbe-plant interaction has been studied before. Marks and associates (2013) showed that the addition of Bradyrhizobium spp. metabolites produced during bacterial growth in liquid medium enhances the performance of soybean $(4.8 \%$ grain yield). Even the simple addition of submicromolar concentration of NF to hydroponically growing seedling of Medicago truncatula, under rhizobial inoculation, increased the number of nodules per plant (Macchiavelli and Brelles-Mariño 2004). In soybean, Molla and associates (2001) found root growth stimulation by the addition of a cell-free supernatant of Azospirillum brasilense $\mathrm{Sp} 7$ or IAA in the greenhouse. To the best of our knowledge, this is the first report about the beneficial effect of combining co-inoculation and treatment with EC (plant and bacteria metabolites) on plant growth and yield.

\section{Conclusion.}

The main achievement obtained during this study was the contribution of the understanding of how alfalfa and the consortium Sinorhizobium-Delftia exchange signaling molecules during an effective interaction. In addition, the results support the idea that the co-inoculation improves agronomic expectations compared with single-rhizobial inoculation. Four days after inoculation, nod gene inducing flavonoids were the main molecular signal detected and possibly involved in the chemical dialog; however, over time, the production of IAA became an important chemical sign that probably was responsible for a major root development. Other chemical signals were also detected as the increase in the secretion of unsaturated and shortchain FA and organic acids derived from lignin degradation; all these molecules are probably involved in membrane fluidization that might prepare the root for rhizobial colonization. The root colonization by JD2 was already shown during this work. Finally, the addition of hydroponic cell-free EC produced during the co-inoculation of alfalfa was enough to increase plant growth of inoculated plants. The results suggest that the secondary metabolites produced during the co-inoculation of alfalfa effectively have plant-growth-promoting activity and may be used in biotechnological formulations.

\section{MATERIALS AND METHODS}

\section{Strains used in this study.}

The bacterial strains used in the present study were Delftia sp. strain JD2 (Morel et al. 2011) and the microsymbiont of $M$. sativa, S. meliloti U143, regularly used in the commercial formulation produced in Uruguay (Castro-Sowinski et al. 2002). Cells were grown in tryptone-yeast (TY) medium (5 g of tryptone, $3 \mathrm{~g}$ of yeast extract, and $0.09 \mathrm{~g}$ of anhydrous $\mathrm{CaCl}_{2}$ per liter) at $30^{\circ} \mathrm{C}$ and $200 \mathrm{rpm}$. Growth was monitored by measuring optical density at $620 \mathrm{~nm}$.

\section{Hydroponic experiments and collection of EC.}

Seed of $M$. sativa 'Crioula' (alfalfa) were surface sterilized (15 min in $20 \% \mathrm{NaClO}$, rinsed with and soaked in sterilized water) and placed on cheesecloth-covered stainless-steel lattices in glass transparent pots containing $400 \mathrm{ml}$ of sterile Howieson medium (Howieson et al. 1993). Containers were incubated in a growth chamber (16 h of light, $8 \mathrm{~h}$ of darkness, and 18 to $22^{\circ} \mathrm{C}$ ). Five days later, plants were transferred to fresh Howieson medium (time-zero) and inoculated with Delftia sp. strain JD2 or S. meliloti U143 $\left(10^{6}\right.$ or $10^{7} \mathrm{CFU} / \mathrm{ml}$ of hydroponic solution, respectively). Control experiments (without inoculation) were also done.

For the analytical evaluation of secreted molecules (plant or bacterial origin), hydroponic EC were collected 4, 7, and 15 days after inoculation and centrifuged at 10,000 rpm for $20 \mathrm{~min}$ to remove root debris and microorganisms. The supernatant was filtered through Whatman number 1 cellulose filter paper (Millipore) and then through $0.45-\mu \mathrm{m}$ nitrocellulose filters. Filtrates were concentrated by lyophilization and stored at $-20^{\circ} \mathrm{C}$. The chemical identification and quantification of molecules of filtrates were performed as described below.

The EC that were used as irrigation solutions (discussed below) were prepared as follows: 4 days after co-inoculation, hydrophonic EC were filtered through Whatman number 1 cellulose filter paper (Millipore) and finally through $0.45-\mu \mathrm{m}$ and $0.2-\mu \mathrm{m}$ nitrocellulose filters to ensure sterilization.

\section{Plant assays.}

Greenhouse experiments were performed as follows: surfacesterilized seed of alfalfa were transferred to $1-\mathrm{kg}$ pots $(12$ pots per treatment, 5 seeds per pot) filled with nonsterile soil/sand/ vermiculite $(2: 2: 1)$. The experimental design was a completely randomized block. When indicated, $100 \mathrm{ml}$ of EC collected from co-inoculated plants (containing molecules from bacterial and plants origin) were used as irrigation solution in pots before sowing. Seed were inoculated with U143 or JD2 $\left(10^{7}\right.$ or $10^{6} \mathrm{CFU}$ per seed, respectively). Two weeks later, two plants per pot were removed. Thinning was based on uniformity of plant growth appearance. Plants were grown in the greenhouse ( 18 to $23^{\circ} \mathrm{C}$ ) and irrigated twice a week (to soil water capacity) with water, 10-fold diluted Jensen medium (Vincent 1970), or calcium hyperphosphate solution (1 g/liter), alternately. Uninoculated control plants supplemented with $\mathrm{KNO}_{3}(0.05 \%)$ and without $\mathrm{N}$ were also done. SDW and RDW were measured after drying at $80^{\circ} \mathrm{C}$ until constant weight.

\section{Visualization of JD2 infection.}

The rhizosphere stable pMP4655 plasmid, expressing green fluorescent protein (GFP) and conferring tetracycline (Tc) resistance as described by Bloemberg and associates (2000), was introduced into electrocompetent cells of Delftia sp. strain JD2, obtained as described by Ferri and associates (2010). Transformation was done in a Gene Pulser-Apparatus connected to the Pulse controller (MicroPulser; Bio-Rad). Transforming JD2 cells were selected on TY plates containing Tc at $40 \mu \mathrm{g} / \mathrm{ml}$ at $30^{\circ} \mathrm{C}$.

For root colonization experiments, the hydroponic systems were inoculated with U143 or JD2-pMP4655 cells. At 4, 7, and 15 days after inoculation, roots were cut and profusely washed in phosphate-buffered saline (PBS) to remove attached particles and placed upon a cover slip in PBS. Samples were examined using an Olympus IX81 microscope equipped with epifluorescence detection. A dichroic filter (UMWIB3) set tailored to the specific chromophore was used (for enhanced GFP, 470/25-nm excitation with 510-nm long pass emission).

\section{Chemical identification and quantification of molecules.}

EC were concentrated by lyophilization, dissolved in water and their qualitative and quantitative chemical compositions were analyzed using different chromatography and elucidation procedures. 
The analysis of flavonoids, IAA, and Trp was done by highperformance liquid chromatography (HPLC)-MS. Lyophilized EC were suspended in $1 \mathrm{ml}$ of deionized water and $20-\mu \mathrm{l}$ aliquots were injected into an HPLC electrospray ionization tandem MS (MS/MS) system. Chromatographic separation was performed using a Perkin Elmer Series 200 HPLC system (Wellesley, U.S.A.) coupled to an Applied Biosystems QTRAP LC/MS/MS system (Foster City, U.S.A.) consisting of a hybrid triple-quadrupole linear ion trap (QqQlit) mass spectrometer equipped with an electrospray ion source. HPLC analyses were performed on a 250-by-72.1-mm Tracer Spherisorb ODS2 C18 reversed-phase column with a particle size of 5 $\mathrm{mm}$ (Teknokroma, Barcelona, Spain). The flow rate was 0.3

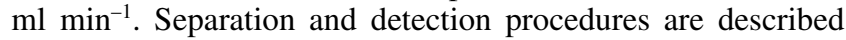
by Dardanelli and associates (2010). The following flavonoids were used as standard for quantitative determination: the flavones apigenin, chrysin, and luteolin; the isoflavone genistein; the flavonol morin; and the flavanones naringenin (aglycone derivative of naringin) and naringin.

The analysis of LMW compounds was done by GC-MS. Lyophilized EC were suspended in $1 \mathrm{ml}$ of deionized water and proteins and polysaccharides were fractionated from LMW secondary metabolites by precipitation with three volumes of acetone/ethanol (1:1). The supernatant was completely dried under vacuum and, finally, the LMW compounds were solubilized in $50 \mu \mathrm{l}$ of acetonitrile and derivatized by silylation using $50 \mu \mathrm{l}$ of $\mathrm{N}$-methyl-N-(trimethylsilyl)trifluoroacetamide (Sigma-Aldrich), as described by Serandour and associates (2008). GC-MS analysis was carried out on a GCMS-QP 2010 ULTRA apparatus (Shimadzu, Tokyo), equipped with an HP5MS capillary column $(30 \mathrm{~m}$ by $0.25 \mathrm{~mm}$ i.d. by $0.25 \mu \mathrm{m})$ (Agilent $\mathrm{J} \& \mathrm{~W}$ ), with helium as gas carrier $\left(1.7 \mathrm{ml} \mathrm{min}^{-1}\right)$ and splitless mode. The oven temperature program was $80^{\circ} \mathrm{C}$ for 2 min, then increased to $290^{\circ} \mathrm{C}\left(8^{\circ} \mathrm{C} \mathrm{min}^{-1}\right)$, maintained for 3 min, increased to $310^{\circ} \mathrm{C}\left(20^{\circ} \mathrm{C} \mathrm{min}^{-1}\right)$, and finally maintained for $10 \mathrm{~min}$. Injector, interface, and ion source temperatures were kept in $300^{\circ} \mathrm{C}$. Mass detector was set in SCAN mode (50 to $850 \mathrm{~m} / \mathrm{z}$ ). Determination of LMW compounds was performed by comparison of mass spectra deposited in commercially available libraries (NIST and Wiley). To confirm the chemical identity of LMW compounds, linear retention index (LRI) (or Kovats index) were calculated by injection of a solution on $n$ alkanes (C9 to $\mathrm{C} 26$ ). In all cases of compounds reported, differences between theoretical and experimental calculated LRI values were smaller than 10 units, confirming MS identification.

Lipid composition was also analyzed by FA methyl esters (FAME) analysis. Lipid extractions and sample preparation were performed as described by Bligh and Dyer (1959) and Paulucci and associates (2014), respectively. FAME composition was analyzed using a Hewlett Packard 5890 Serie II gas chromatograph equipped with a highly nonpolar column (SGL-1) of dimethyl polysiloxane ( $50 \mathrm{~m}$ by $0.25 \mathrm{~mm}$ i.d. by $0.2 \mu \mathrm{m}$ ) (Sugelabor S.A.) and an FID. GC-FID conditions were as follows: injector and detector temperatures of 250 and $300^{\circ} \mathrm{C}$, respectively, and $\mathrm{N}$ as carrier gas. The oven temperature was programmed at $180^{\circ} \mathrm{C}$ for $25 \mathrm{~min}$, then increased by $3^{\circ} \mathrm{C} \mathrm{min}{ }^{-1}$ up to $250^{\circ} \mathrm{C}$ and maintained for $12 \mathrm{~min}$. Peak areas of methyl esters were used to determine relative amounts. FAMEs were identified by comparison with commercial standards (SigmaAldrich, St. Louis).

The monosaccharide composition was also analyzed by GCFID. Sugars were extracted in methanol $(80 \%)$ at $60^{\circ} \mathrm{C}$ for 10 min, followed by centrifugation $(20 \mathrm{~min}, 10,000 \times g)$ and drying the supernatant under $\mathrm{N}_{2}$ flux. Samples were dissolved in dimethylformamide and incubated at $70^{\circ} \mathrm{C}$ for $30 \mathrm{~min}$ with an equal volume of hexamethyldisilazane at room temperature for at least $1 \mathrm{~h}$. Trimethylsylil derivates were analyzed by GC-FID (discussed above). Injector and detector temperatures were kept in 250 and $300^{\circ} \mathrm{C}$, respectively. $\mathrm{N}$ was employed as carrier gas. The oven temperature was programmed at $190^{\circ} \mathrm{C}$ for $4 \mathrm{~min}$, followed by an increase of $15^{\circ} \mathrm{C} \mathrm{min}^{-1}$ up to $250^{\circ} \mathrm{C}$, and then kept for $32 \mathrm{~min}$.

\section{Statistics.}

All experiments were performed at least three times and data were subjected to one-way analysis of variance (ANOVA) analysis using PAST software version 1.56 , with post hoc pairwise comparisons based on Tukey's honestly significant difference test when the ANOVA showed significant inequality of means. Statistical significance was determined at $P=0.05$. Homogeneous groups were designated by superscript letters.

\section{ACKNOWLEDGMENTS}

This work was supported by the National Agency for Research and Innovation (Agencia Nacional de Investigación e Innovación), the Program for the Development of Basic Sciences (Programa de Desarrollo de las Ciencias Básicas), and the Sectorial Commission for Scientific Research (Comisión Sectorial de Investigación Científica). Financial assistance was also provided by CONICET PIP 112-201101-0030. M. S. Dardanelli is a member of the Research Career of CONICET-Argentina.

\section{LITERATURE CITED}

Badri, D., and Vivanco J. M. 2009. Regulation and function of root exudates. Plant Cell Environ. 32:666-668.

Bennett, J. W., Hung, R., Lee, S., and Padhi, S. 2012. Fungal and bacterial volatile organic compounds: An overview. Pages 373-394 in: The Mycota. A Comprehensive Treatise on Fungi as Experimental Systems for Basic and Applied Research and Their Role as Ecological Signaling Agents. K. Esser and B. Hock, eds. Springer-Verlag, Berlin, Heidelberg, Germany.

Bertin, C., Yang, X., and Weston, L. A. 2003. The role of root exudates and allelochemicals in the rhizosphere. Plant Soil 256:67-83.

Bligh, E. G., and Dyer, W. J. 1959. A rapid method for total lipid extraction and purification. Can. J. Biochem. Physiol. 37:911-917.

Bloemberg, G. V., Wijfjes A. H. M., Lamers, G. E. M., Stuurman, N., and Lugtenberg, B. J. J. 2000. Simultaneous imaging of Pseudomonas fluorescens wcs 365 populations expressing three different autofluorescent proteins in the rhizosphere: New perspectives for studying microbial communities. Mol. Plant-Microbe Interact. 13:1170-1176.

Brechenmacher, L., Lei, Z., Libault, M., Findley, S., Sugawara, M., Sadowsky, M. J., Sumner, L. W., and Stacey, G. 2010. Soybean metabolites regulated in root hairs in response to the symbiotic bacterium Bradyrhizobium japonicum. Plant Physiol. 153:1808-1822.

Bullied, W. J., Buss, T. J., and Vessey, J. K. 2002. Bacillus cereus UW85 inoculation effects on growth, nodulation, and $\mathrm{N}$ accumulation in grain legumes: Field studies. Can. J. Plant Sci. 82:291-298.

Caetano-Anollés, G., Crist-Estes, D. K., and Bauer, W. D. 1988. Chemotaxis of Rhizobium meliloti to the plant flavone luteolin requires functional nodulation genes. J. Bacteriol. 170:3164-3169.

Cassán, F., Perrig, D., Sgroy, V., Masciarelli, O., Penna, C., and Luna, V. 2009. Azospirillum brasilense Az39 and Bradyrhizobium japonicum E109, inoculated singly or in combination, promote seed germination and early seedling growth in corn (Zea mays L.) and soybean (Glycine $\max$ L.). Eur. J. Soil Biol. 45:28-35.

Castro-Sowinski, S., Martinez-Drets, G., and Okon, Y. 2002. Laccase activity in melanin-producing strains of Sinorhizobium meliloti. FEMS (Fed. Eur. Microbiol. Soc.) Microbiol. Lett. 209:119-125.

Dakora, F. D., and Phillips, D. A. 2002. Root exudates as mediators of mineral acquisition in low-nutrient environments. Plant Soil 245:35-47.

Dardanelli, M. S., Fernández de Córdoba, F. J., Espuny, M. R., Rodríguez Carvajal, M. A., Soria Díaz, M. E., Gil Serrano, A. M., Okon, Y., and Megías, M. 2008. Effect of Azospirillum brasilense coinoculation with Rhizobium on Phaseolus vulgaris flavonoids and Nod factor production under salt stress. Soil Biol. Biochem. 40:2713-2721.

Dardanelli, M. S., Manyani, H., González-Barroso, S., Rodríguez-Carvajal. M. A., Gil-Serrano, A. M., Espuny, M. R., López-Baena, F. J., Bellogín, R. A. Megías, M., and Ollero, F. J. 2010. Effect of the presence of the plant growth promoting rhizobacterium (PGPR) Chryseobacterium balustinum Aur9 and salt stress in the pattern of flavonoids exuded by soybean roots. Plant Soil 328:483-493. 
Dardanelli, M. S., Fernández de Córdoba, F. J., Estévez, J., Contreras, R. Cubo, M. T., Rodríguez-Carvajal, M. A., Gil-Serrano, A. M., LópezBaena, F. J., Bellogín, R., Manyani, H., Ollero, F. J., and Mejías, M. 2012. Changes in flavonoids secreted by Phaseolus vulgaris roots in the presence of salt and the plant growth-promoting rhizobacteria Chryseobacetrium balustinum. Appl. Soil Ecol. 57:31-38.

Duetz, W. A., Bouwmeester, H., van Beilen, J. B., and Witholt, B. 2003 Biotransformation of limonene by bacteria, fungi, yeasts, and plants. Appl. Microbiol. Biotechnol. 61:269-277.

Dutta, S., Rani, T. S., and Podile, A. R. 2013. Root exudate-induced alterations in Bacillus cereus cell wall contribute to root colonization and plant growth promotion. PLoS One 8:e78369.

Egamberdieva, D., Berg, G., Lindström, K., and Räsänen, L.A. 2010. Coinoculation of Pseudomonas spp. with Rhizobium improves growth and symbiotic performance of fodder galega (Galega orientalis Lam.). Eur. J. Soil Biol. 46:269-272.

Ferri, L., Gori, A., Biondi, E. G., Mengoni, A., and Bazzicalupo, M. 2010. Plasmid electroporation of Sinorhizobium strains: The role of the restriction gene hsdR in type strain Rm1021. Plasmid 63:128-135.

Fox, S. L., O'Hara, G., and Brau, L. 2011. Enhanced nodulation and symbiotic effectiveness of Medicago truncatula when co-inoculated with Pseudomonas fluorescens WSM3457 and Ensifer (Sinorhizobium) medicae WSM419. Plant Soil 48:245-254.

Han, J., Su, L., Dong, X., Cai, Z., Sun, X., Yang, H., Wang, Y., and Song, W. 2005. Characterization of a novel plant growth-promoting bacteria strain Delftia tsuruhatensis HR4 both as a diazotroph and a potential biocontrol agent against various plant pathogens. Syst. Appl. Microbiol. 28:66-76.

Hartwig, U. A., Maxwell, C. A., Joseph, C. M., and Phillips, D. A. 1990 Chrysoeriol and luteolin released from alfalfa seeds induce nod genes in Rhizobium meliloti. Plant Physiol. 92:116-122.

Howieson, J., Ewing, M., Robson, A., and Abbot, L. 1993. External phosphate and calcium concentrations, but not the products of rhizobial nodulation genes, affect the attachment of Rhizobium meliloti to roots of annual medics. Soil Biol. Biochem. 25:567-573.

Itzigsohn, R., Kapulnik, Y., Okon, Y., and Dovrat, A. 1993. Physiological and morphological aspects of interaction between Rhizobium meliloti and alfalfa (Medicago sativa) in association with Azospirillum brasilense. Can J. Microbiol. 39:610-615.

Jayamohan, N. S., and Kumudini, B. S. 2011. Host pathogen interaction at the plant cell wall. Int. Res. J. Pharmacol. 1:242-249.

Jones, D. L. 1998. Organic acids in the rhizosphere-a critical review. Plant Soil 205:25-44.

Juge, C., Prévosta, D., Bertranda, A., Bipfubusaa, M., and Chalifour, F. P. 2012. Growth and biochemical responses of soybean to double and triple microbial associations with Bradyrhizobium, Azospirillum and arbuscular mycorrhizae. Appl. Soil Ecol. 61:147-157.

Khorassani, R., Hettwer, U., Ratzinger, A., Steingrobe, B., Karlovsky, P., and Claassen, N. 2011. Citramalic acid and salicylic acid in sugar beet root exudates solubilize soil phosphorus. BMC Plant Biol. 11:121.

Macchiavelli R. E., and Brelles-Mariño G. 2004. Nod factor-treated Medicago truncatula roots and seeds show an increased number of nodules when inoculated with a limiting population of Sinorhizobium meliloti. J. Exp. Bot. 55:2635-2640.

Marks, B. B., Megias, M., Nogueira, M. A., and Hungría, M. 2013. Biotechnological potential of rhizobial metabolites to enhance the performance of Bradyrhizobium spp., and Azospirillum brasilense inoculants with soybean and maize. AMB Express 3:21.

Mishra, P., Mishra, S., and Selvakumar, G. 2009. Coinoculation of Bacillus thuringeinsis-KR1 with Rhizobium leguminosarum enhances plant growth and nodulation of pea (Pisum sativum L.) and lentin (Lens culinaris L.). World J. Microbiol. Biotechnol. 25:753-761.

Molla, A., Shamsuddin, Z., and Saud, H. 2001. Mechanism of root growth and promotion of nodulation in vegetable soybean by Azospirillum brasilense. Comm. Soil Sci. Plant Anal. 32:2177-2187.

Morel, M., and Castro-Sowinski, S. 2013. The complex molecular signal- ing network in microbe-plant interaction. Pages 169-199 in: Plant Microbe Symbiosis: Fundamentals and Advances. N. K. Arora, ed. Springer, Bangalore, India.

Morel, M., Braña, V., and Castro-Sowinski, S. 2012. Legume crops, importance and use of bacterial inoculation to increase the production. Pages 217-240 in: Crop Plant. A. Goyal, ed. InTech, Rijeka, Croatia

Morel, M. A., Ubalde, M., Braña, V., and Castro-Sowinski, S. 2011. Delftia sp. JD2: A potential $\mathrm{Cr}(\mathrm{VI})$-reducing agent with plant growthpromoting activity. Arch. Microbiol. 193:163-168.

Narula, N., Kothe, E., and Behl, R. K. 2009. Role of root exudates in plant-microbe interactions. J. Appl. Bot. Food Qual. 82:122-130.

Neumann, G. 2007. Root exudates and nutrient cycling. Pages 123-157 in: Soil Biology. Nutrient Cycling in Terrestrial Ecosystem. A. Varma, ed. Springer-Verlag, Berlin, Heidelberg, Germany.

Paulucci, N. S., Dardanelli, M. S., and García de Lema, M. 2014. Biochemical and molecular evidence of a $\Delta 9$ fatty acid desaturase from Ensifer meliloti 1021. Microbiol. Res. 169:463-468.

Peters, N. K., and Long, S. R. 1988. Alfalfa root exudates and compounds which promote or inhibit induction of Rhizobium meliloti nodulation genes. Plant Physiol. 88:396-400.

Peters, N. K., Frost, J. W., and Long, S. R. 1986. A plant flavone, luteolin, induces expression of Rhizobium meliloti nodulation genes. Science 233:977-980.

Phan Tran, L.-S., and Nguyen, H. T. 2009. Future biotechnology of legumes. Pages 265-307 in: Nitrogen Fixation in Crop Production. D. W. Emerich and H. B. Krishnan, eds. Agron. Monogr. 52. American Society of Agronomy, Madison, WI, U.S.A.

Ping, L., and Boland, W. 2004. Signals from the underground: Bacterial volatiles promote growth in Arabidopsis. Trends Plant Sci. 9:263-266.

Rajesh Kannan, V., Suganya, S., King Solomon, E., Balasubramanian, V., Ramesh, N., and Rajesh, P. 2011. Analysis of interaction between Arbuscular mycorrhizal fungi and their helper bacteria by MILPA model. Res. Plant Biol. 1:48-62.

Roudier, F., Gissot, L., Beaudoin, F., Haslam, R., Michaelson, L., Marion, J., Molino, D., Lima, A., Bach, L., Morin, H., Tellier, F., Palauqui, J. C., Bellec, Y., Renne, C., Miquel, M., Dacosta, M., Vignard, J., Rochat, C., Markham, J. E., Moreau, P., Napier, J., and Faure, J. D. 2010. Verylong-chain fatty acids are involved in polar auxin transport and developmental pattering in Arabidopsis. Plant Cell 22:364-375.

Sandnes, A., Eldhuset, T. D., and Wollebæk, G. 2005. Organic acids in root exudates and soil solution of Norway spruce and silver birch. Soil Biol. Biochem. 37:259-269.

Sérandour, J., Reynaud, S., Willison, J., Patouraux, J., Gaude, T., Ravanel, P., Lempérière, G., and Raveton, M. 2008. Ubiquitous water-soluble molecules in aquatic plant exudates determine specific insect attraction. PLoS ONE 3:e3350. Published online.

Shukla, K. P., Sharma, S., Singh, N. K., Singh, V., Tiwari, K., and Singh, S. 2011. Nature and role of root exudates: Efficacy in bioremediation. Afr. J. Biotechnol. 10:9717-9724.

Silva, L. R., Pereira, M. J., Azevedo, J., Mulas, R., Velazquez, E., GonzálezAndrés, F., Valentão, P., and Andrade, P. B. 2013. Inoculation with Bradyrhizobium japonicum enhances the organic and fatty acids content of soybean (Glycine max (L.) Merrill) seeds. Food Chem. 141:36363648 .

Ubalde, M., Braña, V., Sueiro, F., Morel, M., Martínez-Rosales, C., Marquez, C., and Castro-Sowinski, S. 2012. The versatility of Delftia sp. isolates as tools for bioremediation and biofertilization technologies. Curr. Microbiol. 64:597-603.

Vincent, J. M. 1970. A Manual for the Practical Study of Root-Nodule Bacteria. Handb. No. 15. Blackwell Scientific Publications, Oxford.

Volpin, H., Burdman, S., Castro-Sowinski, S., Kapulnik, Y., and Okon, Y. 1996. Inoculation with Azospirillum increased exudation of rhizobial nodgene inducers by alfalfa roots. Mol. Plant-Microbe Interact. 9:388-394.

Zhang, J., Subramanian, S., Zhang, Y., and Yu, O. 2007. Flavone synthases from Medicago trucatula are flavanone-2-hydroxylases and are important for nodulation. Plant Physiol. 144:741-751. 